\title{
As Tecnologias de Informação e Comunicação e sua Influência na Vivência Espaço-Temporal de Trabalhadores Bancários
}

\author{
Information and Communication Technologies and their Influence on the Temporal and \\ Spatial Experience of Bank Workers
}

\author{
Vânia Gisele Bessi ${ }^{1}$ \\ Universidade Feevale / Instituto de Ciências Sociais Aplicadas, Novo Hamburgo - RS, Brasil \\ Dusan Schreiber ${ }^{2}$ \\ Universidade Feevale / Instituto de Ciências Sociais Aplicadas, Novo Hamburgo - RS, Brasil \\ Daniel Pedro Puffal ${ }^{3}$ \\ Universidade do Vale do Rio dos Sinos / Programa de Pós-Graduação em Gestão e Negócios, São Leopoldo - RS, Brasil \\ Vilmar Antonio Gonçalves Tondolo ${ }^{4}$ \\ Universidade de Caxias do Sul / Programa de Pós-Graduação em Administração, Caxias do Sul - RS, Brasil
}

\begin{abstract}
Resumo
O objetivo deste artigo é verificar e analisar como as mudanças no trabalho, advindas do uso intensivo das tecnologias de informação e comunicação (TIC), influenciam a vivência espaço-temporal dos sujeitos no cotidiano do trabalho bancário. O referencial teórico aborda as mudanças no espaço-temporalidade, principalmente aquelas propiciadas pelo uso intensivo das tecnologias nos processos de trabalho, e suas consequências sociais. Foi realizado um estudo de caso em um banco público brasileiro e 29 bancários, de idades, cargos e tempos de empresa diversos foram entrevistados. A pesquisa priorizou uma abordagem qualitativa no tratamento e análise do conteúdo das entrevistas transcritas, priorizando o entendimento do conteúdo implícito nas falas dos sujeitos. O setor bancário apresentou-se como um campo de estudo propício para analisar essa temática, em função das constantes e profundas mudanças que vem enfrentando há décadas, tanto na natureza como nos processos de trabalho. A necessidade de executar um trabalho de forma veloz, associada ao grande volume de atividades e ao reduzido número de bancários, configura-se como elemento potencializador de estresse e de adoecimento para os participantes do estudo.
\end{abstract}

Palavras-chave: Tecnologias de Informação e Comunicação. Espaço-Temporalidade. Trabalho Bancário.

Artigo recebido em 22 de agosto de 2013 e aceito para publicação em 15 de junho de 2015.

\section{DOI: http://dx.doi.org/10.1590/1679-395110605}

${ }^{1}$ Doutora em Administração pelo Programa de Pós-graduação em Administração da UFRGS; Professora Adjunta da Universidade Feevale. Endereço: ERS 239, 2755, Vila Nova, CEP 93525-075, Novo Hamburgo - RS, Brasil. E-mail: vania@feevale.br

${ }^{2}$ Doutor em Administração pelo Programa de Pós-graduação em Administração da UFRGS; Professor Adjunto da Universidade Feevale. Endereço: ERS 239, 2755, Vila Nova, CEP 93525-075, Novo Hamburgo - RS, Brasil. E-mail: dusan@feevale.br

${ }^{3}$ Doutor em Administração pela Universidade do Vale do Rio dos Sinos - UNISINOS; Professor no Programa de Pós-Graduação em Gestão e Negócios da UNISINOS. Endereço: Av. Unisinos, 950, São João Batista, CEP 93022-000, São Leopoldo - RS, Brasil. Email: dpuffal@unisinos.br

${ }^{4}$ Doutor em Administração pela Universidade do Vale do Rio dos Sinos -UNISINOS; Professor do Programa de Pós-Graduação em Administração da Universidade de Caxias do Sul - UCS. Endereço: Rua Francisco Getúlio Vargas, 1130, CEP 95070-560, Caxias do Sul - RS, Brasil. Email: vtondolo@gmail.com 


\begin{abstract}
This article aims to examine and analyze how work changes, derived from intensive use of information and communication technologies (ICTs), influence the temporal and spatial experience of subjects on everyday bank work activities. The theoretical framework addresses changes in spatiality and temporality, mainly those caused by intensive use of technologies in work processes, and their social consequences. A case study in a Brazilian bank was conducted and 29 bank workers, at various ages, positions, and length of service in the company were interviewed. The study prioritized a qualitative approach in data processing and content analysis of transcribed interviews, prioritizing an understanding of the implicit content in subjects' speech. The banking sector showed up as an adequate study field to analyze this theme, due to the constant and profound changes it has faced for decades, both regarding its nature and work processes. The need to perform a job in a fast way, associated with the large volume of activities and the reduced number of bank workers, consists in an element that boosts stress and illness among the study participants.
\end{abstract}

Keywords: Information and Communication Technologies. Spatiality and Temporality. Bank Work.

\title{
Introdução
}

O modelo do trabalho bancário modificou-se muito ao longo das últimas décadas em suas formas de execução e de organização. O tradicional fluxo de papéis, documentos manipulados e contabilizados no trabalho de escrituração do movimento diário dos bancos foi substituído por dados armazenados e manipulados em sistemas eletrônicos, baseados nas tecnologias de informação e comunicação (TIC). As TIC desempenham importante papel nessa nova configuração do trabalho, servindo tanto como suporte à comunicação e transferência de informação quanto como tecnologias relacionais, favorecendo a criação de relações interpessoais entre colegas e clientes (JOLLIVET, 2003).

No ambiente do trabalho bancário, a flexibilidade, a mobilidade e a velocidade, proporcionadas pelas TIC são, ainda, forças importantes de controle dos trabalhadores. O próprio controle, nesse contexto, se diferencia, predominando formas cada vez mais sutis, bem como o autocontrole por parte do sujeito do trabalho e o controle exercido pelos clientes, já que se tornou necessário satisfazê-los a qualquer tempo (PELBART, 2003).

O sujeito do trabalho bancário pode ser caracterizado, nessa nova configuração, como o trabalhador da informação ou, como já mencionava Drucker, na década de 1950, o trabalhador do conhecimento, uma vez que o uso das TIC configura uma demanda por um tipo de trabalho diferenciado daquele originalmente apresentado nos bancos. O objeto do trabalho bancário, a mercadoria-dinheiro, não se modificou e ganhou maior mobilidade, complexidade e velocidade em seu fluxo, características da nova fase capitalista, denominada por Harvey (2001) como acumulação flexível. A proximidade com a clientela do serviço bancário se faz necessária para vencer a concorrência que se acirrou com os movimentos da globalização (LAZZARATO e NEGRI, 2001). As TIC, nesse panorama, têm papel de fundamental importância, já que a capacidade de processamento de informações torna-se um diferencial de empresas e de trabalhadores.

Se por um lado, as TIC constituem-se em elementos facilitadores do trabalho, por outro acarretam, no ambiente de trabalho, mudanças na experimentação espaço-temporal dos sujeitos (VIRILIO, 1997; 1999; 2000), que influenciam todos os níveis da vida social. Essa nova forma de vivência espaço-temporal gera no sujeito um constante sentimento de que o tempo não para. Para Harvey (2001), essas mudanças apresentamse na forma de uma compressão espaço-temporal que transmite o sentimento de que o mundo encolheu. $\mathrm{Na}$ opinião de Virilio (2000), vive-se, contemporaneamente, sob o signo da velocidade, que se acentua e se potencializa por meio do vetor tecnológico. Nesse sentido, as TIC desempenham, na visão do autor, o papel de próteses tecnológicas, que permitem ao sujeito deslocamentos cada vez mais velozes. 
Percebe-se que o sujeito do trabalho, nesse contexto, precisa estar conectado e "a postos" o tempo todo. Trata-se de um sujeito em constante vigília, seja para se manter informado, seja para se manter atualizado e qualificado. O trabalho bancário é, dessa forma, um exemplo paradigmático das transformações presentes no mundo do trabalho, decorrentes, entre outros elementos, do uso intensivo das TIC. Constitui-se, assim, uma realidade peculiarmente favorável e atraente aos estudos sobre a nova configuração espaço-temporal e o papel da tecnologia nessas mudanças.

Nesse contexto, o trabalho, potencializado pelas TIC e compreendido como vetor da lógica da velocidade, tende a ocupar todos os espaços da vida, sendo possível se trabalhar a qualquer tempo e em qualquer lugar. Isso pode acarretar, aos sujeitos do trabalho, sentimentos de ansiedade e aumento do autocontrole, visando a dar conta das demandas. Não são raros os casos, relatados na literatura, de adoecimentos de trabalhadores bancários, em função do ritmo, da sobrecarga e da própria natureza do trabalho (NETZ e MENDES, 2006; OLIVEIRA e CAMPELLO, 2006; JACQUES e AMAZARRAY, 2006).

A partir do exposto, o objetivo deste artigo é verificar e analisar como as mudanças no trabalho, advindas do uso intensivo das TIC, influenciam a vivência espaço-temporal dos sujeitos no cotidiano do trabalho bancário. Para tanto, foi realizado um estudo de caso em um banco público brasileiro, sendo realizadas entrevistas com 6 gestores e 23 trabalhadores bancários com idades, cargos e tempos de empresa variados. Essa diversidade é importante, já que se trata de sujeitos com trajetórias e percepções diferentes, o que enriquece e qualifica a análise.

Acredita-se que a importância do estudo reside em compreender as implicações sociais das constantes demandas por um trabalho em um ritmo cada vez mais acelerado, associadas a intensas cobranças para atingir metas. Esse é o panorama que se apresenta no trabalho bancário na atualidade.

O artigo tem a seguinte estrutura: introdução, apresentação dos os principais elementos teóricos de análise, abordando-se as mudanças no mundo do trabalho, proporcionadas pelo uso das TIC, e sua relação com o espaço-temporalidade; os procedimentos metodológicos são apresentados na seção três; na seção quatro são discutidos e analisados os dados coletados no estudo de caso; e, por fim, elencam-se as considerações finais do estudo.

\section{Referencial Teórico}

As mudanças hodiernas no mundo do trabalho decorrem de uma ampla reestruturação produtiva posta em andamento há várias décadas, e que resultaram em uma nova configuração do sistema capitalista, de forma geral. Processos de mudança como a busca pela superação da rigidez da produção, das relações de trabalho e das limitações espaço-temporais impostas à livre circulação do dinheiro apoiaram-se na flexibilidade dos processos de trabalho, dos mercados de trabalho, dos produtos e dos padrões de consumo (HARVEY, 2001).

Para Harvey (2001), a superação dos limites espaço-temporais foi um dos elementos essenciais para que o capitalismo atingisse um estado de acumulação flexível, superando a rigidez do modelo taylorista-fordista de produção.

Um regime de acumulação descreve a estabilização, por um longo período, da alocação do produto líquido entre consumo e acumulação; ele implica alguma correspondência entre a transformação tanto das condições de produção como das condições de reprodução dos assalariados. Um sistema particular de acumulação pode existir porque o seu esquema de reprodução é coerente. [...] Tem de haver, portanto, uma materialização do regime de acumulação, que toma a forma de normas, hábitos, leis, redes de regulamentação etc. que 
garantam a unidade do processo, isto é, a consistência apropriada entre comportamentos individuais e o esquema de reprodução (HARVEY, 2001, p. 117).

Para o autor, as novas formas organizacionais e as novas tecnologias e, em especial, as TIC, tiveram papel preponderante nesse processo. Com a acumulação flexível, o capitalismo conseguiu, finalmente, vencer ou minimizar barreiras que se colocavam sua expansão (HARVEY, 2001). Para tanto, valeu-se de uma gama de inovações técnicas e organizacionais que envolveram aceleração dos processos físicos, do tempo de giro da produção, obsolescência planejada no consumo levando às acelerações na troca e no consumo e incremento do sistema creditício, dos bancos eletrônicos, etc. Nesse contexto é que a adaptabilidade e a flexibilidade dos trabalhadores se tornaram vitais para o desenvolvimento capitalista (LAZZARATO e NEGRI, 2001).

Dessa forma as novas e atuais formas de gestão estão relacionadas, segundo Harvey (2001), à necessidade de flexibilidade, diante de um mercado cada vez mais exigente e avesso à padronização absoluta dos produtos e serviços. Buscam-se, para fazer diante desse desafio, máquinas e trabalhadores intercambiáveis, que possam adaptar-se às inovações em um curto prazo. Para o autor, a aceleração do ritmo dos processos econômicos e, em consequência, da vida social, bem como o incentivo à criação do mercado mundial, para a redução das barreiras espaciais e para a aniquilação do espaço através do tempo, são elementos onipresentes no processo de modernização do capital.

De acordo com Castells (2000), a descentralização, devido à estruturação das empresas em rede e ao controle cada vez maior da força de trabalho, também é elemento essencial para essa reestruturação do capital. A globalização e as novas TIC, tidas como ferramentas básicas para a reestruturação capitalista, por permitir a flexibilização, exemplificam algumas das grandes forças impulsionadoras das mudanças que levaram à atual configuração do capitalismo e da gestão, e à nova dimensão do trabalho.

As TIC auxiliaram a empresa a atingir a tão esperada flexibilidade espaço-temporal. Apoiada pelas redes de comunicação informacional, a empresa não necessita mais estar fixada territorialmente para exercer seu controle sobre sua própria produção e sobre a força de trabalho (BESSI, ZIMMER e GRISCI, 2007; CARDOSO e SOUZA NETO, 2011; PEREIRA, SEGRE e NASCIMENTO, 2013). Além disso, programas computacionais utilizados nos processos de trabalho agilizam e sistematizam rotinas (JOLLIVET, 2003), mas, igualmente, intensificam o ritmo de trabalho, uma vez que o tempo ganho na automatização não reverte em tempo livre para o sujeito do trabalho, como ressalta Pelbart (2000; 2003).

Para Castells (2000, p. 77-78) a reestruturação do capitalismo e a difusão do informacionalismo são processos inseparáveis em escala global, configurando um paradigma tecnológico:

[...] um paradigma econômico e tecnológico é um grupamento de inovações técnicas, organizacionais e administrativas inter-relacionadas [...]. Em cada novo paradigma, um insumo específico ou conjunto de insumos pode ser descrito como o "fator-chave" desse paradigma caracterizado pela queda dos custos relativos e pela disponibilidade universal.

No paradigma tecnológico vigente, as TIC são percebidas como constitutivas da atual sociedade, que é baseada no trabalho imaterial, que se estabelece a partir da mobilização subjetiva dos trabalhadores (LAZZARATO e NEGRI, 2001). A velocidade na tomada das decisões e implementação de projetos e processos passam a ser preponderantes para a rentabilidade do trabalho (VIRILIO, 1997) e para a eliminação ou minimização das barreiras espaço-temporais. A força de trabalho, nesse cenário, precisa ser altamente preparada, capaz de compreender, implementar e administrar os novos padrões muito mais flexíveis, de inovação tecnológica e orientação de mercado. Além disso, precisa gerir as informações produzidas pelas novas tecnologias, que passam a ser, juntamente com a inovação e a velocidade, os elementos principais de diferenciação. Grisci (2006, p. 327) ressalta que: 
[...] a criatividade e a engenhosidade dos trabalhadores, suas capacidades de gerenciamento da informação e de tomada de iniciativa e de decisão e seu investimento pessoal na tarefa e nas relações, desvalorizados no modo de produção fordista passaram a ser valorizados e exigidos como um dos fatores de competitividade para as empresas na nova relação que se estabelece entre produção e consumo.

O sujeito do trabalho precisa, ainda, aprender a "ganhar tempo", ressalta Pelbart (2000). No entanto, muitas vezes, na ânsia de ganhar o tempo, perde-se, pois, "quanto mais o trabalhador quer ter tempo livre e comprar engenhocas para poder livrar-se das tarefas que lhe tomam tempo, tanto mais tempo ele investe trabalhando para comprar essas engenhocas" (PELBART, 2000, p. 34). No mundo do trabalho bancário, a pressão por produzir cada vez mais no mesmo espaço-tempo acarreta sentimentos de fragilidade, que se revertem, muitas vezes, em estresse e doenças relacionadas ao trabalho (JACQUES e AMAZARRAY, 2006).

Nesse sentido, Pelbart (2000, p. 34) ressalta que "o capital, que até recentemente se apresentava como um doador de trabalho, agora se apresenta como um doador de tempo". Para o autor, o antigo regime capitalista concedia ao sujeito do trabalho um tempo livre, ainda que controlado, para que este pudesse se recompor, se reconstituir. O novo sistema tende, analisa Pelbart (2000), a subsumir esse tempo livre, que deve ser investido em ganhar tempo.

Harvey (2001), utilizando-se das análises de Marshall McLuhan, menciona que, além da premência da "gestão do tempo", à medida que o espaço parece encolher em uma "aldeia global" de telecomunicações e em uma "espaçonave terra" de interdependências (entre elas, a econômica), o sujeito do trabalho se vê forçado a aprender a lidar com um avassalador sentido de compressão do espaço e do tempo.

A compressão espaço-temporal, segundo o autor, advém dos "processos que revolucionaram as qualidades objetivas do espaço e do tempo a ponto de nos forçarem a alterar, às vezes radicalmente, o modo como representamos o mundo para nós mesmos" (HARVEY, 2001, p. 219). Refere, ainda, que a história do capitalismo, em geral, caracterizou-se pela aceleração do ritmo de vida, ao mesmo tempo em que venceu as barreiras espaciais em tal grau que, por vezes, o mundo parece encolher.

O "impacto desorientado e disruptivo" (HARVEY, 2001, p. 257) da compressão espaço-temporal ocorre sobre as práticas político-econômicas, sobre o equilíbrio do poder de classe, bem como sobre a vida social e cultural do sujeito, em geral. Para os trabalhadores, há uma intensificação dos processos de trabalho e uma aceleração na desqualificação e requalificação necessárias ao atendimento de novas necessidades de um trabalho cada vez mais relacionado às características do trabalho imaterial (LAZZARATO, 1997; 2004; LAZZARATO e NEGRI, 2001). O trabalho passa a ser "considerado como o processo de desenvolvimento e de aplicação de saberes, de competências, de conhecimentos e de informações: em suma, de emprego de recursos humanos e de mobilização de inteligência prática" (ALMEIDA, 2005, p. 49).

A compressão espaço-temporal provoca um sentimento de diluição de fronteiras e de certa vertigem, já que se faz necessário um exercício constante, por parte do sujeito, de desterritorialização e de reterritorialização, em novas bases, muito mais flexíveis (BAUMAN, 1999; 2001). Nesse sentido, o capitalismo, no contexto contemporâneo da acumulação flexível, ao buscar a superação das limitações espaço-temporais impostas à livre circulação dos capitais, busca, no perfil do sujeito do trabalho contemporâneo, as características que precisa para prosperar e para pôr em prática seu projeto hegemônico.

O trabalhador do conhecimento deve ser um sujeito desterritorializado e, antes de qualquer coisa, desterritorializável. Nesse constante deslocamento, as próteses tecnológicas, em especial as TIC, impulsionam e permitem os movimentos cada vez mais velozes (PELBART, 2000). Como analisa Christlieb (2000), a contemporaneidade é a época da rapidez e da transitoriedade, as palavras que orientam os indivíduos contemporâneos são sair, viajar, ir-se. Segundo o autor, ações como residir e habitar representam 
uma volta ao passado, pois significam um apego a uma territorialização que não é mais valorizada no presente.

Com o imperativo da velocidade, da fluidez e dos fluxos rápidos, descontínuos e ilimitados, a maioria da população sedentária é dominada pela elite nômade e extraterritorial (BAUMAN, 2001). Os nômades são aqueles que se movem por vontade própria, são aqueles para os quais o espaço tem pouca ou nenhuma importância, pois estão sempre fora de lugar, independente do lugar onde estejam. Os nômades quando ocupam algum espaço, logo em seguida o desocupam e seguem viagem, em busca de novos lugares. Os sedentários, por sua vez, quando se movem é porque não lhes resta outra possibilidade.

Assim, mesmo que o sujeito do trabalho sinta-se herdeiro da lógica sedentária, o mundo do trabalho, transformado pelo uso das TIC, o leva a uma importante desterritorialização, a um nomadismo. Isso é particularmente observável no mundo do trabalho bancário onde a forma de trabalhar mudou consideravelmente nas últimas décadas (GRISCI e BESSI, 2004), levando o sujeito a viver e a trabalhar sob novas bases, muito mais fluidas e onde o nomadismo é frequente, com constantes transferências e deslocamentos de um espaço a outro.

Faz-se importante destacar, ainda, que a experimentação espaço-temporal está relacionada aos operadores de tempo, às tecnologias que produzem esta ou aquela experiência, vivência, ideia ou forma do tempo, como ressalta Pelbart (1998). Enfatiza-se que a atual experimentação espaço-temporal do sujeito do trabalho contemporâneo precisa ser pensada a partir de um atravessamento da tecnologia, levando-se em conta a lógica da velocidade, que é o imperativo do sistema capitalista atual.

As TIC possibilitam, ainda, segundo Zarifian (2002a; 2002b), que a empresa contemporânea produza uma modulação que pode ser de três formas. A primeira é a modulação da utilização do tempo: se o computador é o mote desse novo cenário, ele permite sua utilização, a qualquer tempo, mesmo ligado em rede. "O trabalho (assalariado) pode então se libertar radicalmente dos horários legais e se tornar modulável, no sentido de uma variação de sua efetividade e intensidade a qualquer momento" (ZARIFIAN, 2002b, p. 28-29). A segunda é a modulação no espaço: se for possível trabalhar a qualquer tempo, também é possível um alargamento dos espaços de trabalho. Pode-se trabalhar em casa, no carro, na escola, na rua, etc. A terceira é a modulação do engajamento subjetivo: o próprio sujeito do trabalho aciona sua atividade e modula o espaço-tempo em que a realizará. "Mas isso supõe um forte compromisso de sua parte: ele deve por si mesmo se obrigar a fazê-lo" (ZARIFIAN, 2002b, p. 28-29, grifo do autor).

Especialmente no mundo do trabalho bancário, as TIC configuram-se como importantes operadores de tempo, além de exercer grande influência na experimentação espaço-temporal dos trabalhadores, em função da intensa automatização dos processos de trabalho. Isso leva o sujeito do trabalho bancário a processos de desterritorialização e reterritorialização, em que o espaço virtual, das tecnologias, tem papel fundamental e a mudança assume caráter de inevitabilidade e de presença constante no cotidiano do trabalho (GRISCI e BESSI, 2004).

Face ao exposto, percebe-se que as mudanças no mundo do trabalho bancário estão intimamente relacionadas à introdução das TIC, demandando um novo posicionamento do sujeito do trabalho e conduzindo-os a uma nova vivência espaço-temporal. Para visualizar esses elementos no cotidiano do trabalho, procedeu-se esta pesquisa, cujos procedimentos metodológicos estão expostos a seguir.

\section{Procedimentos Metodológicos}

O estudo realizado é uma pesquisa qualitativa. Pode-se, ainda, caracterizá-lo como pesquisa descritiva, tendo sido realizado um estudo de caso em um banco público. 
Demo (2000; 2001) refere que métodos qualitativos de pesquisa são essenciais para que se possa entender a complexa realidade contemporânea. Para o autor, a metodologia qualitativa privilegia o lado subjetivo dos fenômenos, sem desconsiderar a objetividade do contexto, buscando depoimentos de pessoas, que se transformam em dados relevantes.

Bauer, Gaskell e Allum (2004), ao analisar a pesquisa social de tipo qualitativa, referem que, nesse tipo de investigação, a comunicação é fator primordial. Em função disso, o interesse se concentra no que as pessoas que fazem parte do grupo pesquisado têm a dizer sobre o que é importante para si, o que pensam sobre suas ações e sobre as ações dos outros. A pesquisa realizada buscou o entendimento de uma realidade social complexa que é o trabalho bancário contemporâneo, privilegiando as percepções e as vivências do sujeito do trabalho, sem deixar de levar em conta o contexto objetivo onde esse trabalho se desenvolve.

A pesquisa descritiva tem como principal finalidade a descrição das características de determinada população ou fenômeno ou, então, o estabelecimento de relações entre variáveis (ROESCH, 1999). Os estudos de caso, segundo Stake (1999) caracterizam-se como uma estratégia de pesquisa interessante quando o interesse do pesquisador limita-se a uma unidade de análise. Segundo o autor, a decisão pelo estudo de caso não ocorre, necessariamente, porque a unidade estudada representa outros casos ou porque ilustra uma característica ou problema particular. A escolha metodológica se dá pelo interesse despertado nas particularidades do caso, que instigam o pesquisador.

A escolha do caso único se deu em função de o banco já ter sido objeto de estudo em outras pesquisas, com temáticas diversas da aqui proposta. Com isso, o acesso torna-se mais facilitado para aprovação da pesquisa. Inicialmente, pretendia-se realizar a pesquisa em mais bancos, o que não foi permitido por aqueles que foram consultados, no momento de elaboração do escopo da pesquisa.

Para a coleta de dados, utilizaram-se fontes documentais e entrevistas semiestruturadas com gestores e trabalhadores bancários. O recurso da entrevista, na pesquisa qualitativa, é utilizado "para mapear e compreender o mundo da vida dos respondentes e é o ponto de entrada para o cientista social que introduz, então, esquemas interpretativos para compreender a narrativa dos atores" (GASKELL, 2004, p. 65). As entrevistas individuais e semiestruturadas têm como principal objetivo conhecer as percepções e sentimentos dos entrevistados sobre um tema específico (GASKELL, 2004).

Todas as entrevistas foram realizadas no local de trabalho dos entrevistados, em horários de expediente interno das agências. Portanto, as entrevistas ocorreram antes ou depois do atendimento ao público externo e contaram com a anuência dos gerentes gerais das agências, que também foram entrevistados. Para ter acesso às agências, solicitou-se a permissão das devidas superintendências, que são os setores hierarquicamente superiores, na estrutura do banco. Foi encontrada grande dificuldade para a realização das entrevistas, sendo que, em alguns casos, foi necessária mais de uma visita para se realizar um único contato, em função da sobrecarga de trabalho. As entrevistas seguiram um roteiro semiestruturado, a partir do objetivo e do que se pretendia analisar na vivência dos sujeitos. Todas foram gravadas e transcritas e tiveram tempos de duração variados, de trinta a noventa minutos.

A utilização das fontes documentais contribui para a caracterização do objeto de estudo e para o entendimento do contexto onde os sujeitos da pesquisa estão inseridos. Segundo Stake (1999), o instrumento de coleta de dados, nos estudos de caso, deve ser objetivo e com poucas perguntas, ainda que complexas. Em função disso, as fontes documentais configuram-se importantes fontes de informações complementares.

O banco pesquisado solicitou sigilo em relação à sua identificação. Em função disso será chamado de BA. A coleta de dados ocorreu em oito agências localizadas em Porto Alegre - RS. Os entrevistados constituem-se em 6 ocupantes de cargos de gerência geral e 23 de cargos variados (inclusive alguns com cargos de gerências intermediárias) e estão indicados no Quadro 1. Salienta-se que se procurou compor um grupo com 
pessoas com diferentes níveis de formação, idade, tempo de empresa e cargos, visando à diferenciação nas percepções acerca da problemática da pesquisa.

Quadro 1

Sujeitos da pesquisa entrevistados no estudo de caso - BA

\begin{tabular}{|c|c|c|c|c|c|}
\hline Entrevistado & Idade & $\begin{array}{l}\text { Tempo de } \\
\text { Empresa }\end{array}$ & Sexo & Função & Formação \\
\hline 1) Gerente 1 & 42 & 19 anos & $M$ & Gerente Geral & Pós-graduação \\
\hline 2) Gerente 2 & 40 & 18 anos & $\mathrm{F}$ & Gerente Geral & Mestrado \\
\hline 3) Gerente 3 & 53 & 25 anos & $\mathrm{M}$ & Gerente Geral & Superior Completo \\
\hline 4) Gerente 4 & 53 & 27 anos & M & Gerente Geral & Superior Completo \\
\hline 5) Gerente 5 & 52 & 29 anos & M & Gerente Geral & Superior Completo \\
\hline 6) Gerente 6 & 48 & 18 anos & $\mathrm{M}$ & Gerente Geral & Superior Completo \\
\hline 7) Bancário 1 & 42 & 18 anos & $F$ & Atendimento & Superior Completo \\
\hline 8) Bancário 2 & 28 & 4 anos & $\mathrm{F}$ & Técnico de Fomento & Superior Completo \\
\hline 9) Bancário 3 & 45 & 18 anos & $\mathrm{F}$ & Caixa & Superior Completo \\
\hline 10) Bancário 4 & 43 & 19 anos & $\mathrm{F}$ & Avaliador Comercial & Superior Completo \\
\hline 11) Bancário 5 & 35 & 4 anos & M & Técnico Bancário & Superior Incompleto \\
\hline 12) Bancário 6 & 45 & 23 anos & $\mathrm{M}$ & Gerente Atendimento & Superior Completo \\
\hline 13) Bancário 7 & 50 & 7 anos & $F$ & Gerente Atendimento & Ensino Médio Completo \\
\hline 14) Bancário 8 & 51 & 23 anos & $\mathrm{F}$ & Caixa & Superior Completo \\
\hline 15) Bancário 9 & 30 & 6 anos & $\mathrm{F}$ & Técnico Operações & Superior Incompleto \\
\hline 16) Bancário 10 & 44 & 26 anos & $M$ & Atendimento & Superior Completo \\
\hline 17) Bancário 11 & 53 & 30 anos & $\mathrm{F}$ & Caixa & Superior Completo \\
\hline 18) Bancário 12 & 29 & 6 anos & $\mathrm{F}$ & Assistente Negócios & Superior Completo \\
\hline 19) Bancário 13 & 50 & 30 anos & $M$ & Avaliador Comercial & Superior Completo \\
\hline 20) Bancário 14 & 51 & 24 anos & M & Caixa & Superior Incompleto \\
\hline 21) Bancário 15 & 45 & 18 anos & $\mathrm{M}$ & Escriturário & Superior Incompleto \\
\hline 22) Bancário 16 & 32 & 2 anos & M & Técnico Bancário & Superior Completo \\
\hline 23) Bancário 17 & 46 & 27 anos & $\mathrm{M}$ & Es criturário & Pós-graduação \\
\hline 24) Bancário 18 & 27 & 7 anos & $\mathrm{F}$ & Assist. Administrativo & Superior Completo \\
\hline 25) Bancário 19 & 53 & 22 anos & $\mathrm{M}$ & Gerente Relacionamento & Superior Completo \\
\hline 26) Bancário 20 & 27 & 7 anos & $M$ & Gerente Relacionamento & Superior Incompleto \\
\hline 27) Bancário 21 & 50 & 28 anos & $\mathrm{F}$ & Escriturária & Superior Completo \\
\hline 28) Bancário 22 & 28 & 4 anos & $F$ & Assist. Administrativo & Pós-graduação \\
\hline 29) Bancário 23 & 51 & 28 anos & $\mathrm{F}$ & Técnico Habitação & Ensino Médio Completo \\
\hline
\end{tabular}

Fonte: Elaborado pelos autores. 
A análise dos dados coletados tanto nas fontes documentais quanto nas entrevistas transcritas seguiu orientação qualitativa, a partir da proposta da metodologia da hermenêutica de profundidade (THOMPSON, 1995; DEMO, 2001). Essa metodologia procura analisar as formas simbólicas, provenientes de falas, ações, documentos, etc., sendo, para isso, necessário captar não somente seu sentido aparente, mas, sobretudo, os sentidos implícitos e as "manhas e artimanhas" das falas comprometidas nas relações (DEMO, 2001). As categorias de análise do estudo foram: i) trabalho bancário cotidiano - procurou-se identificar e analisar como o trabalho está organizado e quais as principais demandas do trabalho bancário; e ii) configuração espaço-temporal dos sujeitos do trabalho - buscava-se o entendimento de como os trabalhadores bancários estão distribuídos espacialmente e como se estrutura sua percepção de tempo, atravessada pelo vetor TIC. No Quadro 2 são ilustradas as questões utilizadas, no roteiro de entrevistas, para analisar as duas categorias.

Quadro 2

Categorias de análise e perguntas aos respondentes

\begin{tabular}{|l|l|}
\hline \multicolumn{1}{|c|}{$\begin{array}{c}\text { Categorias de } \\
\text { Análise }\end{array}$} & \multicolumn{1}{c|}{ Perguntas aos Respondentes } \\
\hline $\begin{array}{l}\text { Trabalho } \\
\text { bancário } \\
\text { cotidiano }\end{array}$ & $\begin{array}{l}\text { Fale sobre como o trabalho está organizado entre os colegas, tanto no que se refere } \\
\text { aue mudano do espaço físico, quanto ao que se refere aos tempos e ritmos de trabalho. } \\
\text { Quais são, em sua opinião e considerando seu trabalho, as principais fontes de } \\
\text { pressão que encontra? } \\
\text { Como você e seus colegas costumam reagir a essas pressões? } \\
\text { Há necessidade de realização de horas extras no seu trabalho? Se há, por quê? O que } \\
\text { fazem nessas horas extras? E há necessidade de levar atividades para realizar em } \\
\text { casa? }\end{array}$ \\
\hline $\begin{array}{l}\text { Configuração } \\
\text { espaço- } \\
\text { temporal dos } \\
\text { sujeitos do } \\
\text { trabalho }\end{array}$ & $\begin{array}{l}\text { Que tipo de tecnologia usa no seu trabalho? Como usa? } \\
\text { Comparando seu trabalho hoje com o período em que entrou no banco, quais as } \\
\text { principais diferenças que pode apontar? } \\
\text { Como você administra seu tempo para conseguir realizar todas as suas atividades no } \\
\text { seu trabalho? } \\
\text { Você considera que existe, atualmente, pressão do tempo para realização das } \\
\text { atividades entre os bancários? De onde vem essa pressão? Como você costuma } \\
\text { reagir a ela? }\end{array}$ \\
\hline
\end{tabular}

Fonte: Elaborado pelos autores.

Thompson (1995) assinala a importância de utilizar as falas do próprio sujeito envolvido no fenômeno que se quer estudar. Para o autor, as falas, as ações, os textos, etc., são formas simbólicas, ou seja, construções significativas que, por essa razão, necessitam de interpretação. Por isso, para Thompson (1995), quando os pesquisadores oferecem uma interpretação de um fenômeno social, eles estão, na verdade, fazendo uma reinterpretação de um campo que já foi pré-interpretado. A interpretação em profundidade, segundo o autor, poderia fazer com que o sujeito, ao tomar conhecimento dela, pudesse se enxergar de maneiras diferentes, possibilitando uma nova interpretação sobre sua própria realidade. Portanto, os sujeitos pesquisados ocupam um papel especial, pois são considerados "sujeitos capazes de compreender, de refletir e de agir, 
fundamentados [na] compreensão e na reflexão" (THOMPSON, 1995, p. 359), além de ser visualizados sempre como inseridos em tradições sociais. A seguir, os resultados da pesquisa.

O conteúdo das entrevistas foi analisado, levando-se em conta o conjunto total dos dados. Com o objetivo de ilustrar e corroborar os dados apresentados, utilizaram-se falas dos sujeitos da pesquisa, consideradas exemplos daquilo que se depreendeu da análise da totalidade das entrevistas.

\section{Apresentação e Discussão dos Resultados}

Esta seção apresenta elementos do trabalho bancário no Brasil, depois faz uma breve caracterização do banco estudado e a análise, a partir das categorias elencadas, dos dados coletados nas entrevistas.

\section{Trabalho bancário no Brasil}

A atual configuração do trabalho bancário brasileiro se deve a um processo de transformação que foi intensificado nas últimas décadas. Segundo Jinkings (2002), com a crescente importância do setor terciário da economia, foram sendo implementadas modificações no sistema financeiro nacional com o objetivo de adequá-lo às necessidades da nova organização industrial e de dinamizar o processo de acumulação capitalista.

A entrada dos bancos estrangeiros no país, que se intensificou a partir da década de 1990, promoveu uma nova concepção de serviço bancário. As instituições estrangeiras tinham entre suas peculiaridades, a prestação de assessoria aos clientes para auxiliá-los na aplicação de seus recursos. No Brasil, até então, isso era privilégio de poucos clientes.

Em relação à automação bancária, Jinkings (2002) refere que as três grandes forças que a impulsionaram nos bancos brasileiros foram a concorrência interbancária, com a criação do banco múltiplo e a possibilidade de atração de novos clientes pela oferta de novos produtos; a agilização do fluxo das informações bancárias; e a expectativa de redução de custos, em face do aumento da produtividade.

O trabalho bancário brasileiro, nesse panorama, vem se mostrando um exemplo paradigmático da reestruturação produtiva do trabalho a partir dos processos de reorganização interna e externa e da inclusão das novas tecnologias. Exemplos de automatização são: a disseminação de caixas automáticos em todas as agências bancárias, caixas 24 horas e os chamados home banking, internet banking ou mobile banking (transações via telefone fixo ou equipamentos móveis), bem como a criação dos chamados "correspondentes não bancários" ligados em rede aos bancos que representam.

A automação do trabalho bancário mostra-se ainda não concluída, já que houve, em 2010, um crescimento acentuado no número de postos eletrônicos de autoatendimento, comparativamente com o número de agências. Segundo dados da Federação Brasileira de Bancos - Febraban (2012a), entre os anos de 2006 e 2010, houve um crescimento de $9,5 \%$ no número de agências bancárias e de $24 \%$ nos postos de trabalho, enquanto que o total de correspondentes não bancários aumentou em 126,2\% e de $\mathrm{ATMs}^{5}$ em locais públicos subiu 59,9\%. Em relação aos ATMs, em 1994 havia 32 mil terminais de autoatendimento no Brasil, em 2011 somavam-se 182 mil equipamentos instalados (FEBRABAN, 2012b). No que se refere ao número de bancos em território nacional, em 2001 havia 182 e em 2009 esse número caiu para 158 (FEBRABAN, 2012c).

\footnotetext{
${ }^{5}$ Os terminais automatic teller machines (ATM) permitem aos clientes fazer transações de autoatendimento, nos caixas automáticos, em qualquer lugar e em qualquer tempo.
} 
Destes, 88 eram bancos privados nacionais com ou sem participação estrangeira, 60 eram privados estrangeiros e com controle estrangeiro e 10 eram bancos públicos federais ou estaduais.

Todo esse panorama de mudanças configurou a necessidade, por parte dos bancos, de um perfil de trabalhador bancário diferenciado. Um trabalhador que passou a se constituir em um sujeito de respostas cada vez mais rápidas para um trabalho que se tornou, a cada dia, mais ágil. $\mathrm{O}$ bancário da atualidade, especialmente aquele que trabalha nas agências, acima de tudo, exerce a função de um consultor de negócios. As atividades burocráticas da administração cotidiana do trabalho bancário têm sido transferidas para os serviços de retaguarda. Quando os bancos optaram por não manter esse serviço de retaguarda, visando ao corte de gastos com pessoal, tais atividades precisaram ser realizadas fora do expediente bancário, como mencionaram entrevistados na pesquisa.

A partir dessa visão panorâmica acerca do trabalho bancário brasileiro, apresentam-se, a seguir, breves considerações acerca do banco estudado, aqui denominado BA.

\section{Breve caracterização do BA}

O BA é um grande banco público brasileiro. É uma instituição centenária e tem atuação em todo o território nacional. Atualmente, conta com mais de 70 mil empregados em todo o país e possui mais de 44 mil postos de atendimento, entre agências e correspondentes não bancários (website do $\mathrm{BA}$ ). $\mathrm{O}$ número de empregados teve um importante incremento nos últimos anos, uma vez que em 2002 girava em torno de 55 mil. Em relação ao perfil atual, $45,8 \%$ são mulheres, $39 \%$ têm entre 18 e 35 anos de idade e $73 \%$ possuem diploma de nível superior (graduação, pós-graduação, mestrado ou doutorado).

Conforme divulgado em seu website, o BA vem mantendo um crescimento contínuo na sua base de clientes contando, ao final do ano de 2012 com mais de 58 milhões de clientes. Também em outros indicadores, o BA se sobressaiu nos últimos anos, divulgando ser o banco brasileiro com maior volume de depósitos à vista e depósitos em poupança. Em relação à sua história, sua missão e aos seus valores, entre outros, é possível perceber que o BA busca, atualmente, posicionar-se como um "banco moderno e competitivo".

O BA tem uma história de processos de reestruturação que se iniciaram, mais intensamente, a partir do ano de 1995. O programa implementado nesse ano é, até a atualidade, apontado como um "divisor de águas no $B A$ " (GERENTE 1). A partir desse programa, a empresa iniciou um processo irreversível de mercantilizarão de sua atividade que, até então, se concentrava em uma atuação predominantemente social (GRISCI e BESSI, 2004). Os entrevistados justificam esse posicionamento, alegando que o banco precisa dar lucros para manter sua atuação social.

O BA implementou três Programas de Apoio à Demissão Voluntária desde a década de 1990, o que fez com que a cultura de estabilidade existente no banco fosse abalada, acenando aos bancários que a demissão do BA era possível e, mais do que isso, desejada. Soma-se a esse fator, o volume de admissões dos últimos anos cujos bancários jovens mostram-se mais propensos a aceitar o projeto atual e competitivo da organização.

Mudanças aconteceram, também, no layout das agências desde o início da reestruturação. A arquitetura das agências contempla a segmentação de clientes, um novo modo de gestão implantado no BA em 2002 e revisto em 2004. Da segmentação resultou a estratificação dos clientes pessoa física de acordo com a renda e/ou a rentabilidade que pudessem proporcionar ao banco. A própria estratificação dos clientes leva a uma diferenciação espacial dos trabalhadores, em função dos clientes que atendem, conforme o entrevistado, Gerente 4.

A partir dos processos de reestruturação, também uma alteração no quadro gerencial foi posta em curso. Algumas agências tiveram o número de gerentes diminuído, e outras, ampliado. O quadro gerencial de uma agência é composto pelo gerente geral e, em alguns casos, gerentes intermediários de segmentos. Quanto 
mais alto o segmento, ou seja, quanto maior o poder de aplicação de recursos que o cliente possui, mais individualizado é seu atendimento. Alguns grandes clientes, como mencionam os gerentes gerais, não se deslocam até o banco. Nesse caso, o gerente é que vai até o cliente, o que demonstra a mobilidade que o banco assume, deslocando-se a procura de rentabilidade. Essa prática elimina barreiras espaço-temporais, pois o horário e o local de atendimento são definidos pelo cliente, podendo ocorrer a qualquer tempo e lugar. Tais características condizem com a descrição de Harvey (2001) acerca das características do estágio atual da acumulação flexível, quando há uma compressão espaço-temporal.

Vale ressaltar que, de 1989 a 2000 o BA passou por um período sem contratações de novos empregados. A partir de 2000 iniciaram novas contratações, que foram intensificadas nos últimos anos em função da necessidade de substituição de empregados terceirizados e aposentados. Essa é, inclusive, uma das reclamações dos entrevistados, pois a empresa contratou um empregado a cada três trabalhadores terceirizados substituídos, intensificando o acúmulo de trabalho para os bancários do BA.

É clara a preferência de alguns gerentes gerais pelo trabalho dos novos bancários, em detrimento dos mais antigos. O Gerente 3 associa os jovens a crianças: "os novos são como crianças, prontos a aprender tudo, o funcionário novo é como uma esponja, que absorve tudo". Nesta fala, percebe-se que há uma ideia de que os empregados novos na empresa são mais facilmente moldáveis, estão mais abertos e aptos a ocuparem espaços que só são ocupados por aqueles suficientemente maleáveis, tal como o indivíduo descrito por Bauman (2001). Outro gerente geral os associa a máquinas: "os novos estão com o HD limpinho, sem vícios" (GERENTE 6).

Os novos empregados, admitidos a partir de 2000, apresentam algumas particularidades em relação aos antigos. Possuem uma nomenclatura de cargos diferenciada e um direcionamento comercial que não se encontrava nos empregados mais antigos. Isso faz com que esses funcionários assumam cargos de gerência com certa rapidez, o que, em alguns momentos, cria mal-estar entre os colegas com mais tempo de empresa, como foi possível perceber nas entrevistas.

A pressão exercida sobre o grupo de bancários do BA é acentuada em função do número reduzido de empregados, decorrente das demissões realizadas por ocasião dos Programas de Demissão Voluntária implementados. O ajuste do quadro de funcionários, com o aumento no número de contratações, tem sido uma das bandeiras de luta dos órgãos representativos da classe dos bancários.

Outra reivindicação, além do aumento de bancários, que também se faz presente nas mensagens do Sindicato e da Associação de Pessoal do $\mathrm{BA}^{6}$ aos trabalhadores associados é a questão da jornada de trabalho. Há um esforço da entidade no sentido de sensibilizar o bancário da importância de parar e, efetivamente, desligar-se da empresa. A dificuldade que o bancário apresenta em "desligar-se" é reflexo de uma necessidade, presente no mundo do trabalho atual, de que o sujeito do trabalho esteja sempre conectado, sempre a postos. Lembra Pelbart (2000) que o sujeito contemporâneo vive a ânsia de ganhar tempo e, nesse sentido, relaxar e descansar é visto como perder tempo. No intuito de não perder tempo, os limites espaço-temporais do trabalho diluem-se, adentrando e ocupando todo o espaço-tempo de vida, inclusive, o das férias. Nesse sentido, essa supressão de limites é favorecida pelas TIC, já que os bancários, como tantos outros trabalhadores, tem acesso aos seus e-mails corporativos a partir de qualquer lugar, o que faz com que possa trabalhar em qualquer espaço-tempo.

Pelbart (2000) lembra, ainda, que o capitalismo de base taylorista concedia ao sujeito do trabalho um espaçotempo livre para que pudesse se recompor, o que não acontece da mesma forma na atual acumulação flexível. Visando a analisar mais detidamente esse aspecto, apresenta-se a seção a seguir, com as implicações das mudanças advindas do uso intensivo das TIC na vivência espaço-temporal dos sujeitos bancários do BA.

\footnotetext{
${ }^{6}$ Órgão de representação dos trabalhadores, formado por empregados do BA, para fins de negociações internas.
} 


\section{Espaço-temporalidade no cotidiano do trabalho no BA: tecnologias de informação e comunicação e a internalização da urgência do tempo}

As categorias de análise utilizadas no presente estudo são trabalho bancário cotidiano e configuração espaçotemporal dos sujeitos do trabalho. Optou-se por abordá-las em paralelo uma vez que, no caso estudado, apresentam-se imbricadas, sendo praticamente impossível dissociá-las.

A configuração espaço-temporal do trabalho no BA apresenta-se, tal como a literatura aponta, permeada pela instabilidade e pela fluidez das fronteiras (HARVEY, 2001; BAUMAN, 2001). O principal fator que culminou com as características encontradas atualmente no BA foi a reestruturação propiciada pelos sucessivos projetos de mudanças implementados a partir de 1995. Essas mudanças repousaram, principalmente, na estratégia de segmentação de clientes que teve início em 2001, nos novos modelos de gestão e na introdução de sistemas informatizados de acompanhamento e controle do trabalho.

Percebe-se, pelas respostas dos entrevistados, que há uma intensificação da velocidade do atendimento (VIRILIO, 1997) dos clientes com menor rentabilidade, em uma tentativa do BA em direcionar os movimentos e os esforços dos bancários para os clientes mais rentáveis, conforme informações do entrevistado Bancário 17. Por outro lado, atender rápido também é uma necessidade em função de que, nos últimos anos houve uma significativa redução no número de caixas, que são os que atuam nos espaços destinados aos não clientes. Dessa forma, para dar conta de todo o público a atender, a velocidade no atendimento também se faz necessária e já está internalizada, conforme os entrevistados, na forma de autocontrole dos próprios bancários em relação aos seus movimentos.

As mudanças às quais os bancários do BA estão expostos não cessam de acontecer, inclusive as propiciadas pelas TIC, o que exige sua constante desterritorialização. Para que a adaptação aconteça, o controle dos pares e o autocontrole são elementos essenciais. Assim, se a relação com a empresa se alterou, as relações entre colegas também, dando ao sujeito do trabalho bancário do BA uma sensação de estar à deriva, como definido por Sennett (2005). Os laços de solidariedade não se sustentam mais, pois "os laços sociais levam tempo pra surgir, enraizando-se devagar nas fendas e brechas das instituições" (SENNETT, 2005, p. 24). Nas organizações contemporâneas e, em especial do cotidiano do trabalho do BA, vive-se a premência do curto prazo. Em função disso, não se estabelece o amadurecimento de sentimentos de confiança entre colegas, $o$ que restringe mecanismos de resistência. Isso é facilmente percebido na segmentação existente entre antigos e novos funcionários e entre aqueles que ocupam funções de gestão e comerciais e os caixas.

A própria segmentação dos clientes constitui-se como importante elemento de diferenciação entre os sujeitos do trabalho. Como os clientes pertencentes a segmentos mais rentáveis estão separados espacialmente, essa separação também se reflete entre os colegas. Atender aos segmentos de clientes mais rentáveis significa um status diferenciado entre os bancários, o que influencia as próprias relações estabelecidas entre os funcionários.

Os gestores compartilham a ideia de que os bancários mais novos são aqueles que se permitem o desenraizamento e a desterritorialização com mais naturalidade. Justamente por isso, é entre os bancários mais novos que se encontra o sentimento de curto prazo a permear suas relações com os bancos. Os novos bancários do BA compartilham um sentimento de que o trabalho no banco é uma atividade transitória e que assim que outras possibilidades melhores venham a surgir, estarão aptos e prontos a se desligarem. É em razão do ritmo intenso e do excesso de trabalho, portanto, que muitos desistem e desligam-se do banco.

Existe, conforme relatado pelo Bancário 17, uma disputa acirrada pelos lugares mais visados no BA, uma vez que a promoção é a única possibilidade de aumento salarial vislumbrada pelos bancários. Em função disso é que muitos desejam assumir posições de gerência nas agências. Essa disputa é incentivada pelos gerentes gerais, que utilizam diversas estratégias para motivar os bancários, acenando-lhes com possíveis futuras promoções. Exemplos dessas estratégias verificam-se entre os "gerentes provisórios" (substitutos 
temporários dos gerentes gerais) que são escolhidos entre aqueles que apresentam melhores resultados de vendas. Outra estratégia é a permissão para que se candidatem aos processos seletivos internos, via sistema de gerenciamento de pessoas, somente aqueles que possuem melhores resultados. Há, também, um discurso de que os mais jovens têm mais garra e vontade de crescer e ocupar esses lugares.

O tempo tal como apresentado por Harvey (2001), Bauman (2001) e Virilio (1997) é fator preponderante na atual configuração espaço-temporal, particularmente visível no trabalho bancário do BA. O tempo, para os bancários entrevistados, é o ponto mais crítico do trabalho contemporaneamente, sendo, inclusive, apontado como a maior fonte de pressão que enfrentam no seu cotidiano. A pressão relativa ao tempo concentra-se não somente na gestão da empresa, mas, igualmente, nos clientes:

\begin{abstract}
No atendimento tu tens que ser rápido porque a fila está ali, no caixa tem que ser rápido porque o cara está ali, nos outros segmentos também tu tens prazos pra cumprir e meta pra cumprir, tem ações que tem que ser para um mesmo dia, tu não pode esperar outro dia. Então tu tens um determinado horário para chegar e cumprir a tarefa. Dependendo do que tu faça tem a pressa porque está chegando o horário e tu tens que cumprir aquilo ali senão vai ficar para o outro dia e pode gerar um transtorno. Nesse sentido sempre tem muita pressão (BANCÁRIO 5).
\end{abstract}

A quantidade de pessoas que precisam atender, com um número reduzido de empregados e, além disso, a necessidade constante de atendimento das metas faz com que a velocidade na execução das atividades seja uma demanda constante no cotidiano do trabalho bancário. A velocidade constitui-se, tal como refere Virilio (1997) em elemento gerador de riqueza, pois, quanto mais rápido se atende (sem, no entanto, perder a eficácia da venda), mais clientes podem ser atendidos durante o dia de trabalho. Com isso, para alguns bancários, a carga horária normal de trabalho torna-se insuficiente para a realização de todas as atividades necessárias, havendo a necessidade constante de realização de horas extraordinárias, ainda que não seja disseminada para todos os bancários da agência.

Na questão do relacionamento com o cliente, as TIC proporcionam que os bancários possam reconhecer o perfil daqueles clientes que estão atendendo, oferecendo-lhes produtos que eles não estariam, voluntariamente, dispostos a adquirir. Nos sistemas informatizados, mensagens lembram o bancário que ele deve oferecer determinado produto àquele cliente objeto de consulta. Isso gera, segundo relatos dos entrevistados, certa angústia, já que, em muitos casos, outras pessoas esperam atendimento. Nesse caso, os sistemas informatizados configuram-se como importantes fontes geradoras de estresse, como menciona, especialmente, o Bancário 4: "aquela coisa piscando, enquanto você atende o cliente vai gerando uma ansiedade que a gente até perde a concentração e depois fica se culpando, pensando se poderia ter feito um atendimento melhor".

Na busca pela sobrevivência na rotina diária, as TIC ocupam duplo papel no trabalho bancário: de herói e de vilão, como apontam os entrevistados. No que se refere ao papel de herói, os bancários são unânimes em dizer que sem as novas tecnologias seria impossível trabalhar. Nesse sentido, o sujeito do trabalho bancário está cotidianamente suportado pelas próteses tecnológicas, como refere Pelbart (2003) e Virilio (1997). Os bancários referem que as TIC facilitam, agilizam e dão mais segurança ao trabalho. Por outro lado, o papel de vilão é lembrado ao julgar que os sistemas informatizados utilizados no BA, por não ser, em alguns casos, interligados e apresentar-se excessivamente pesados, constituem-se como principais entraves para a agilização dos processos de trabalho. Os entrevistados lembram, no entanto, que a informatização foi um dos elementos decisivos para a redução no número de empregados, o que é, hoje, um dos grandes problemas do BA, como mencionado.

As constantes transformações propiciadas pelas TIC não permitem que os empregados consigam acompanhá-la na velocidade exigida pelo BA, segundo os entrevistados: 


\begin{abstract}
Eu acho que a informática faz atropelar, ir rápido nas coisas, a informação chega rápido, a resposta vem rápido, então aquilo funciona rápido, e a mudança vem e às vezes nem se tem tempo de se adaptar, ainda mais quem tem um pouco mais de tempo de BA, eu, por exemplo, vou fazer 24 anos de BA, então às vezes eu não tenho tempo de me adaptar muito, eu nem me adaptei aquilo e já tá mudando, tem que ficar no computador e entrar no mundo da informática, se não tu não acompanhas (BANCÁRIO 14).
\end{abstract}

As TIC, portanto, constituem importantes elementos de controle, no sentido de exigir do sujeito do trabalho constante atualização e vigília permanente para "dar conta" das demandas que se apresentam em termos de tecnologia e de qualificação. As TIC permitem, também, que outro importante controle seja exercido sobre o trabalhador bancário. Trata-se da atividade de retaguarda cuja finalidade é fiscalizar a conformidade do trabalho da agência.

A retaguarda é a "segurança de que a coisa vai ser bem feita" (BANCÁRIO 4). As atividades de retaguarda ou de back office, presentes em todas as agências do BA, fiscalizam a execução do trabalho bancário, seja analisando a documentação física, seja verificando os sistemas informatizados utilizados para a consecução das funções diárias. Os controles realizados pelos funcionários de retaguarda servem de instrumento de controle das gerencias que podem, por meio de seus relatórios, verificar os atendimentos e as tarefas realizadas por todos os bancários, estipular e cobrar metas, controlar acessos aos sistemas, etc.

Dessa forma, ao realizar seu trabalho, os bancários sabem que estão sob constante vigilância eletrônica, tal como apontaram estudos realizados com esse público (BESSI, ZIMMER e GRISCI, 2007; CARDOSO e SOUZA NETO, 2011; PEREIRA, SEGRE, e NASCIMENTO, 2013). Esse controle, em alguns casos, é simplesmente introjetado e naturalizado, mas, em outros casos, configura-se como fonte de estresse e angústia no trabalho, já que os bancários tem a necessidade de dar conta das suas atividades no tempo necessário, exigido pela gestão. Com isso, todo o tempo de trabalho passa a ser rigorosamente controlado, visando à maior produtividade. Esse tempo de trabalho não se restringe ao estipulado em contrato, mas ao tempo necessário à realização das atividades (que são, sempre, em maior volume) o que, via de regra, se estende para além do tempo de trabalho acordado, configurando extensas jornadas, nem sempre remuneradas. Não é incomum, segundo os sujeitos entrevistados, a necessidade de levar trabalho para ser realizado em casa, já que o tempo no banco já não é mais suficiente para cumprir com todas as demandas que se impõem.

Assim, embora o banco extrapole os limites espaço-temporais do trabalho, em uma implosão do tempo (HARVEY, 2001), ao sujeito do trabalho não é permitido utilizar o espaço-tempo de trabalho para outras atividades que não as demandadas pela gestão. Procurando ocupar todo o espaço-tempo do sujeito do trabalho com tarefas relacionadas diretamente à atividade produtiva, o banco tenta restringir a produção de outros modos de subjetividade, já que também não há tempo para o fortalecimento de laços de solidariedade entre colegas, o que é corroborado pelos entrevistados:

No passado nós, colegas, nos encontrávamos fora daqui, combinávamos jantas, passeios juntos. A gente gostava de ficar junto, tinha vontade de ficar com os amigos que eram nossos colegas até mesmo nos finais de semana. Hoje, a gente não tem tempo nem de tomar um café juntos no horário de expediente. É todo mundo sempre correndo, sempre de mau humor, a gente não tem mais prazer em ficar juntos, não temos mais união, não temos mais vontade de ver ninguém fora daqui (BANCÁRIO 23).

O autocontrole também se faz notar no cotidiano do trabalho bancário do BA. Os bancários, além dos controles definidos pelo banco, criam seus próprios controles paralelos. Visando a controlar sua atividade, elaboram planilhas, montam check list, etc. Em alguns casos, esses controles são repassados aos colegas para 
que também os utilizem. Nesse sentido, mesmo com o uso das TIC nas rotinas de trabalho, há uma busca por maiores elementos de controle, no afã de fazer o trabalho bem feito e dentro dos prazos estipulados.

O trabalho bancário, no BA, permeado pelas TIC e associado às exigências da gestão e da clientela, configura-se, atualmente, como um ambiente potencializador de estresse e de sofrimento. No que se refere à vivência espaço-temporal dos sujeitos, percebe-se que há uma intensificação no ritmo de trabalho, que está, em parte, naturalizada. Essa velocidade que se impõe, aliada à possibilidade (e, por vezes, à necessidade) de levar trabalho para fazer em casa ou de atender o cliente onde quer que ele esteja, faz com que o trabalho bancário extrapole os limites do próprio banco, configurando a implosão espaço-temporal descrita por Harvey (2001).

\section{Considerações Finais}

Neste trabalho foram verificados e analisados como as mudanças no trabalho, advindas do uso intensivo das TIC, influenciam a vivência espaço-temporal dos sujeitos no cotidiano do trabalho bancário. Para tanto, foram entrevistados 29 bancários de um banco público brasileiro, além de ter-se levado em conta o contexto objetivo do setor bancário brasileiro e do banco objeto do estudo.

No que se refere à atual configuração espaço-temporal do trabalho, autores como Bauman (1999; 2001); Harvey (2001) e Virilio (1999; 2000), mostraram-se fundamentais para entender a lógica hegemônica da gestão do trabalho bancário. O BA se mostrou paradigmático em relação ao panorama do capitalismo flexível, já que, para dar conta das atividades que lhes são impostas, os bancários extrapolam o horário normal de trabalho e, não raro, levam trabalho para ser realizado em suas casas. Esses elementos configuram a implosão espaço-temporal mencionada por Harvey como uma das características determinantes do capitalismo flexível.

A atual configuração espaço-temporal do trabalho bancário, que prima pelo ritmo intenso de trabalho, pela individualização dos esforços e pela segmentação de clientes e de bancários tende a limitar, de maneira acentuada, os laços de solidariedade como apontou Sennett (2005), em uma nítida expressão de que os sentimentos e as histórias de vida já não mais são compartilhadas. No caso estudado, verificou-se esse panorama de forma clara, podendo-se analisar, ainda, que o sentimento de urgência e premência do tempo, impostos pela introdução das TIC no cotidiano do trabalho e pelos modos de gestão implantados pelo banco, mostram-se intensamente nas atitudes dos bancários, que desenvolvem o autocontrole e o controle dos pares, para dar conta das demandas.

O imperativo da velocidade e da aceleração se fez notar, expresso tanto nas exigências da gestão, quanto na pressão dos clientes. A necessidade de executar um trabalho de forma veloz, atrelada ao grande volume de atividades, configura-se como elemento potencializador de estresse e de adoecimento para os bancários. A preocupação que o bancário já tem internalizada, em relação às necessidades do cliente, afeta, inclusive, sua decisão em aderir às manifestações coletivas como as greves, por exemplo. Isso foi particularmente visível no discurso dos bancários do BA.

O trabalho bancário é considerado, tanto por aqueles em cargos operacionais, quanto por aqueles em cargos de gerência, como um trabalho que extrapola os limites espaço-temporais do banco. O imperativo da velocidade, potencializado pelas tecnologias, transforma-se, igualmente, em elemento impeditivo da resistência, já que o tempo para parar, refletir e agir de outra forma que não aquela imposta pela gestão dos bancos, apresenta-se sempre reduzido. Percebe-se que os bancários tidos pela gerência como os mais jovens, estão mais propensos a aceitar a atual configuração espaço-temporal do trabalho bancário, uma vez que, ao ingressarem no banco, o trabalho lhes foi apresentado dessa forma. 
O trabalho bancário é permeado de paradoxos e a especificidade da rotina nas atividades bancárias é mais um deles. Se por um lado, as normas e os procedimentos tendem a um trabalho padronizado, por outro lado, as demandas dos clientes fazem com que o trabalho apresente-se diferente a cada dia, com particularidades a ser atendidas, além das metas a ser cumpridas.

Os sistemas informatizados do BA, por apresentarem-se, em alguns casos, lentos e pesados, acabam configurando mais um paradoxo ao sujeito do trabalho contemporâneo. Se permitem, por um lado, ganhar tempo, agilizando o atendimento (já que, embora lentos, os sistemas fazem com que o trabalho apresente-se mais rápido do que no passado, quando os processos eram, em sua maioria manuais), por outro, geram certa angústia, quando "travam telas", solicitam muitas informações e não são totalmente interligados, fazendo com que haja retrabalho.

A atual configuração espaço-temporal do trabalho no BA, proporcionada pelos modelos de gestão implantados pelo banco e pela introdução das TIC no ambiente de trabalho, faz com que os próprios bancários, na busca pela satisfação incondicional dos clientes e o atendimento das metas que lhe são imputadas, desenvolvam mecanismos de aceleração e de velocidade na execução de suas tarefas cotidianas. As relações que estabelecem com seus clientes estão atravessadas pelas TIC, pelas formas de controle institucionalizadas pela gestão do BA e pelo próprio autocontrole. Tem-se, portanto, que as TIC influenciam fortemente a vivência espaço-temporal dos sujeitos do trabalho, imprimindo-lhes ritmo acelerado, sentimento de urgência, em uma implosão das barreiras do espaço e do tempo.

Algumas limitações se impuseram ao estudo, como a impossibilidade de realizar observações diretas do cotidiano do trabalho bancário (o que teria enriquecido e ampliado a análise) e a dificuldade de acesso aos bancários. Tem-se, portanto, como limitação do estudo, o fato do estudo estar limitado a agências em Porto Alegre e de um único banco, com características e particularidades próprias. A limitação geográfica e de respondentes deve-se à dificuldade de acesso a agências de outras cidades ou, mesmo, a um número maior de agências e de trabalhadores bancários.

Considera-se que a contribuição para a área de conhecimento centra-se, em especial, na possibilidade de se lançar um novo olhar sobre uma temática já amplamente estudada, que são as mudanças no mundo do trabalho advindas do uso intensivo das TIC.

Recomenda-se, como ampliação do estudo, a coleta de dados em outras cidades, visando à comparação, bem como o estudo de outros segmentos.

Finalizando, cabe ressaltar que, por se tratar de um estudo de caso, não é possível generalizar as análises.

\section{Referências}

ALMEIDA, P. P. Serviço(s) e sociologia do trabalho: que práticas? Que objectos? Sociologia, Problemas e Práticas, n. 47, p. 47-67, 2005.

BAUER, M. W.; GASKELL, G.; ALLUM, N. C. Qualidade, quantidade e interesses do conhecimento: evitando confusões. In: BAUER, M. W.; GASKELL, G. (Orgs.). Pesquisa qualitativa com texto, imagem e som: um manual prático. Petrópolis, RJ: Vozes, 2004. 17-36 p.

BAUMAN, Z. Globalização: as consequências humanas. Rio de Janeiro: Jorge Zahar, 1999.

BAUMAN, Z. Modernidade líquida. Rio de Janeiro: Jorge Zahar, 2001. 
BESSI, V. G.; ZIMMER, M. V.; GRISCI, C. L. I. O panóptico digital nas organizações: espaço-temporalidade e controle no mundo do trabalho contemporâneo. Organizações \&Sociedade, v. 14, n. 42, p. 83-96, 2007.

CARDOSO, M. F.; SOUZA NETO, M. V. Vigilância eletrônica no trabalho bancário: do controle consentido ao totalitarismo corporativo. In: ENCONTRO DE ADMINISTRAÇÃO DA INFORMAÇÃO, 3., 2011, Porto Alegre. Anais... Porto Alegre: [s.n], 2011.

CASTELLS, M. A sociedade em rede. São Paulo: Paz e Terra, 2000.

CHRISTLIEB. P. F. El territorio instantáneo de la comunidad posmoderna. In: LINDÓN, A. (Coord.).La vida cotidiana y su espacio-temporalidad.México, DF: UNAM, 2000.147-170 p.

DEMO, P. Metodologia do conhecimento científico. São Paulo: Atlas, 2000.

DEMO, P. Pesquisa e informação qualitativa. São Paulo: Papirus, 2001. (Coleção Papirus Educação).

DRUCKER, P. F. Knowledge-worker productivity. California Management Review, v. 41, n. 2, p. 79-94, 1999.

FEBRABAN. Bancarização. Disponível em: <http://www.febraban.org.br/7Rof7SWg6qmyvwJcFwF7I0aSDf9jyV/ sitefebraban/BANCARIZA\%C7\%C3O\%20-\%20III\%20Congresso\%20Latino\%20Americano\%20de\%20bancariza\%E7 $\%$ E3o\%20e\%20Microfinan\%E7as\%20-\%20FELABAN\%20-\%20JUNHO\%202011\%20-\%20FINAL.pdf>. Acesso em: 10 dez. 2012a.

FEBRABAN. O setor bancário em números. Disponível em: <http://www.febraban.org.br/7Rof7SWg6qmyvwJ cFwF7I0aSDf9jyV/sitefebraban/Ciab\%20FEBRABAN_Pesquisa\%20Setor\%20Banc\%E1rio\%20em\%20Numeros\%202 011.pdf>. Acesso em: $10 \mathrm{dez} .2012 \mathrm{~b}$.

FEBRABAN. Dados estatísticos do setor. Disponível em: <http://www.febraban.org.br/bd/FRProjetos.asp ?id_grupo=760\&id_pastaMA=52\&id_assuntoMA=414 \&id_assuntoME=0\&id_assunto=414\&id_item=0 >. Acesso em: 10 dez. 2012c.

GASKELL, G. Entrevistas individuais e grupais. In: BAUER, M. W.; GASKELL, G. (Orgs.). Pesquisa qualitativa com texto, imagem e som: um manual prático. Petrópolis, RJ: Vozes, 2004.64-89 p.

GRISCI, C. L. I. Trabalho imaterial. In: CATTANI, A. D.; HOLZMANN, L. (Orgs.). Dicionário de trabalho e tecnologia. Porto Alegre: Ed. UFRGS, 2006. 456-458 p.

GRISCI, C. L. I.; BESSI, V. G. Modos de trabalhar e de ser na reestruturação bancária. Sociologias, n. 12, p. 160-201, 2004.

HARVEY, D. Condição pós-moderna. São Paulo: Loyola, 2001.

JACQUES, M. G. C.; AMAZARRAY, M. R. Trabalho bancário e saúde no paradigma da excelência. Boletim da Saúde, v. 20, n. 1, p. 93-105, 2006.

JINKINGS, N. Trabalho e resistência na "fonte misteriosa": os bancários no mundo da eletrônica e do dinheiro. Campinas, SP: Ed. Unicamp, 2002.

JOLLIVET, P. N. TIC e o trabalho cooperativo reticular: do conhecimento socialmente incorporado à inovação sociotécnica. In: COCCO, G.; GALVÃO, A. P.; SILVA, G. (Orgs.). Capitalismo cognitivo: trabalho, redes e inovação. Rio de Janeiro: DP\&A, 2003.83-107 p.

LAZZARATO, M. Pour une redéfinition du concept de 'bio-politique'. Futur Antérieur, n. 39-40, [s.p.], septembre 1997. Disponível em <http://www.multitudes.net/Pour-une-redefinition-du-concept/>. Acesso em 30 de setembro de 2013. 
LAZZARATO, M. From capital-labour to capital-life. Ephemera, v. 4, n. 3, s. 1., p. 187-208, 2004.

LAZZARATO, M.; NEGRI, A. Trabalho imaterial: formas de vida e produção de subjetividade. Rio de Janeiro: DP\&A, 2001.

McLUHAN, M. La galaxie Gutenberg. Montréal.Montréal: Toronto University Press, 1962.

NETZ, J. A.; MENDES, J. M. R. O massacre dos trabalhadores bancários e a ação sindical: sobre jornadas, metas excessivas, pressão, medo, práticas gerenciais autoritárias versus práticas preventivas. Boletim da Saúde, v. 20, n. 1, p. 93-105, 2006.

OLIVEIRA, P. A. B.; CAMPELLO, J. C. Cargas de trabalho e seu impacto sobre a saúde: estudo de caso em quatro instituições financeiras em Porto Alegre. Boletim da Saúde, v. 20, n. 1, p. 93-105, 2006.

PELBART, P. P. Rizoma temporal. Educação, Subjetividade e Poder, v. 5, n. 5, p. 60-63, 1998.

PELBART, P. P. A vertigem por um fio: políticas de subjetividade contemporânea. São Paulo: Fapesp/Iluminuras, 2000.

PELBART, P. P. Vida capital: ensaios de biopolítica. São Paulo: Iluminuras, 2003.

PEREIRA, C. L.; SEGRE, L. M.; NASCIMENTO, R. P. A ampliação das estruturas de controle por meio das tecnologias de informação e comunicação: onipresença do "pan-óptico eletrônico" no setor bancário. Cad. EBAPE.BR, v. 11, n. 1 , p. $65-84,2013$.

ROESCH, S. M. A. Projetos de estágio e de pesquisa em administração: guia para estágios, trabalhos de conclusão, dissertações e estudos de caso. São Paulo: Atlas, 1999.

SENNETT, R. A corrosão do caráter: consequências pessoais do trabalho no novo capitalismo. Rio de Janeiro: Record, 2005.

STAKE, R. E. Investigación con estudio de casos. 2. ed. Madrid: Morata, 1999.

THOMPSON, J. B. Ideologia e cultura moderna: teoria social crítica na era dos meios de comunicação de massa. Petrópolis, RJ: Vozes, 1995.

VIRILIO, P. Velocidade e política. São Paulo: Estação Liberdade, 1997.

VIRILIO, P. A bomba informática. São Paulo: Estação Liberdade, 1999.

VIRILIO, P. Cibermundo: a política do pior. Lisboa: Teorema, 2000.

ZARIFIAN, P. O tempo do trabalho: o tempo-devir frente ao tempo espacializado. Tempo Social, Revista de Sociologia da USP, v. 2, n. 14, p. 1-18, 2002a.

ZARIFIAN, P. Engajamento subjetivo, disciplina e controle. Novos Estudos CEBRAP, n. 64, p. 23-31, 2002 b. 